\title{
ASSESSMENT OF THE MULTI-GNSS PPP PERFORMANCE USING PRECISE PRODUCTS FROM THE WUHAN ANALYSIS CENTRE
}

Weiguo $\mathrm{Li}^{1,2}$ and Michal Kačmařík ${ }^{1}$

${ }^{1}$ Department of Geoinformatics, VŠB-Technical University of Ostrava, Ostrava, 708 00, Czech Republic

2School of Land Science and Space Planning, Hebei GEO University, Shijiazhuang, 050031, China Correspondence to: Weiguo Li (weiguo.li.st@vsb.cz)

https://doi.org/10.31490/9788024845050-9

\begin{abstract}
Performance of the Precise Point Positioning (PPP) technique for GNSS positioning is strongly dependant on a quality of used satellite orbit and clock product. Within this study, three different versions of precise products provided by the analytical centre of the Wuhan University were evaluated by processing various combinations of GNSS systems constellations over a five months long period in 2020 with RTKLIB software. The results show that final and rapid version of the precise products could offer a centimetre level of positioning accuracy in static daily PPP while the ultra-rapid version utilizing 24 hours of predicted products performed significantly worse. In this regard, a positive effect on positioning accuracy was reached when including Galileo signals in processing of the ultrarapid version product. When studying coordinate's repeatability over the selected time period, the best results were obtained for a combination of GPS and GLONASS signals.
\end{abstract}

Keywords: Precise Point Positioning, multi-GNSS, precise products

\section{INTRODUCTION}

Development of new Global Navigation Satellite Systems (GNSS) as Galileo (GAL) or BeiDou Navigation Satellite System (BDS) as well as a modernization of legacy systems GPS and GLONASS (GLO) is linked with a transition from single or dual constellation solutions to multi-GNSS combined solutions. Alongside, advanced positioning techniques based on undifferenced observations as the Precise Point Positioning (PPP) technique (Zumberge et al., 1997) can provide accurate results only if high-quality precise products (satellite ephemerides and satellite clock error corrections) are available as they cannot cancel some of the significant errors by differencing observations from pairs of receivers.

Various evaluations of GNSS post-processing precise products quality were published in recent years. Their authors focused either on an evaluation of the satellite orbits and clocks themselves (i.e. Guo et al., 2017, Montenbruck et al., 2017, Li et al., 2020, Steigenberger and Montenbruck, 2020) or on quantifying their impact on positioning in terms of coordinates accuracy, precision and optionally also on a convergence time of PPP solutions ( $\mathrm{Li}$ et al., 2017, Geng et al., 2018, Bahadur and Nohutcu, 2019 or Zhou et al., 2020). The purpose of this study is to provide an idea on which version of precise product provided by the analytical center at Wuhan University and what combination(s) of GNSS constellations can currently 
provide the most accurate PPP positioning in Europe and in China.

\section{MATERIALS AND METHODS}

\subsection{Dataset}

Wuhan University (http://www.igs.gnsswhu.cn/) run two analysis centres (ACs) belonging to the International GNSS Service (IGS). One of them is a standard IGS analysis centre with an abbreviation WHU while the other one with an abbreviation WUM belongs to the IGS Multi-GNSS Experiment (MGEX). Existing analysis centres (ACs) including the Wuhan's standardly provide three versions of precise products labelled as final, rapid and ultra-rapid, which differ in accuracy, update rate and sampling rate. Within the presented study, the final product from the Wuhan University MGEX solution (Guo et al., 2016) and the rapid and ultrarapid products from the Wuhan University IGS solution were used. In case of the ultra-rapid product, its predicted part including extrapolated satellite ephemerides and satellite clock error corrections was utilized.

Table 1. Overview of the different type products from WUHAN ACs.

\begin{tabular}{|c|c|c|c|c|c|c|}
\hline Institution & $\begin{array}{l}\text { Product } \\
\text { type }\end{array}$ & ID & Constellations & File period & $\begin{array}{l}\text { Sampli } \\
\text { ng rate }\end{array}$ & $\begin{array}{l}\text { Update } \\
\text { rate }\end{array}$ \\
\hline Wuhan & final & $\begin{array}{l}\text { WUM0MGX } \\
\text { FIN }\end{array}$ & $\begin{array}{c}\text { GPS+GLO+GAL+B } \\
\mathrm{DS} 2+\mathrm{BDS} 3+\mathrm{QZSS}\end{array}$ & $24 \mathrm{~h}$ fitted & $15 \mathrm{~min}$ & weekly \\
\hline $\begin{array}{l}\text { Univ. } \\
\text { MGEX }\end{array}$ & $\begin{array}{l}\text { ultra- } \\
\text { rapid }\end{array}$ & $\begin{array}{c}\text { WUM0MGX } \\
\text { ULA }\end{array}$ & $\begin{array}{l}\text { GPS }+ \text { GLO+GAL+B } \\
\text { DS2+BDS3+QZSS }\end{array}$ & $\begin{array}{c}24 \mathrm{~h} \text { fitted }+24 \mathrm{~h} \\
\text { predicted }\end{array}$ & $5 \mathrm{~min}$ & 1 hour \\
\hline \multirow{3}{*}{$\begin{array}{c}\text { Wuhan } \\
\text { Univ. } \\
\text { IGS }\end{array}$} & final & whs & $\begin{array}{c}\text { GPS+GLO+GAL+B } \\
\text { DS2+QZSS }\end{array}$ & $24 \mathrm{~h}$ fitted & $15 \mathrm{~min}$ & weekly \\
\hline & rapid & whr & $\begin{array}{c}\mathrm{GPS}+\mathrm{GLO}+\mathrm{GAL}+\mathrm{B} \\
\mathrm{DS} 2+\mathrm{QZSS}\end{array}$ & $24 \mathrm{~h}$ fitted & $15 \mathrm{~min}$ & daily \\
\hline & $\begin{array}{l}\text { ultra- } \\
\text { rapid }\end{array}$ & whu & $\begin{array}{c}\text { GPS+GLO+GAL+B } \\
\text { DS2+QZSS }\end{array}$ & $\begin{array}{c}24 \mathrm{~h} \text { fitted }+24 \mathrm{~h} \\
\text { predicted }\end{array}$ & $15 \mathrm{~min}$ & 3 hours \\
\hline
\end{tabular}

Data collected at eight GNSS stations over 152 consecutive days from January till May 2020 were used in this study. All eight GNSS stations are part of the global IGS MGEX network and equipped with multi-GNSS hardware. Position of stations is presented in Figure 1. 


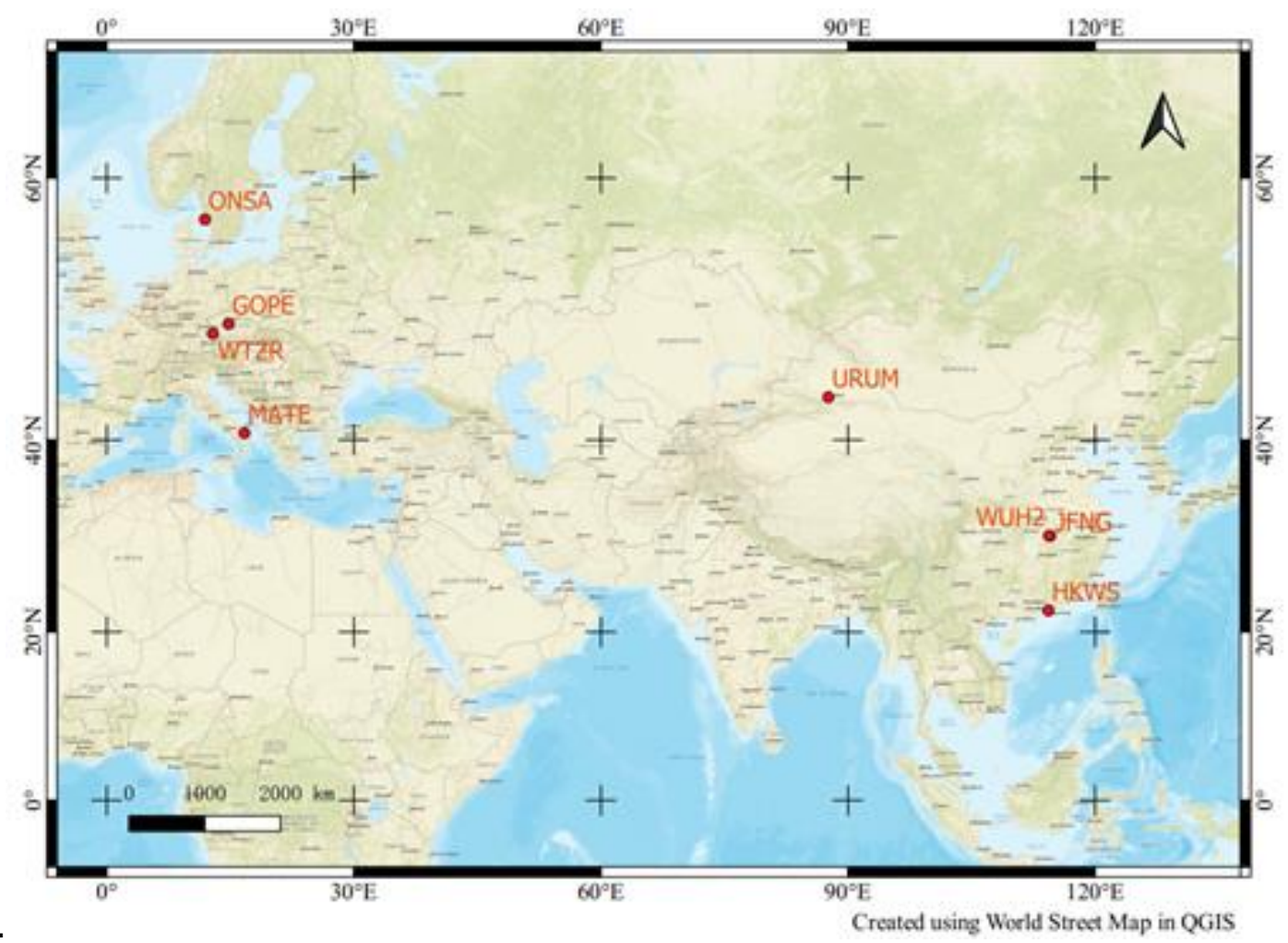

Fig. 1. Geographical distribution of the selected eight GNSS stations used in the study.

\subsection{Data processing}

RTKLIB open source library for GNSS navigation and positioning (Takasu, 2009, http://www.rtklib.com) in version 2.4.3 b34 was used for GNSS processing. It supports various undifferenced and double-differenced positioning techniques for real-time and postprocessing solutions while supporting GPS, GLO, GAL, BDS and QZSS signals. Basic information about PPP processing strategy applied in this study are presented in Table 2. Daily observation files from individual GNSS stations were processed to estimate their coordinates in the static mode. Although the ultra-rapid product is being updated hourly by the $A C$ at Wuhan University, a single file available before the processing run for a given day was entering the processing. It therefore corresponds to using 24 hours of predicted product.

Table 2. The processing strategy for PPP used for the three different types of precise products from the Wuhan university analysis center.

\begin{tabular}{cc}
\hline Processing mode & PPP-static in 24h window \\
\hline Strategy & forward extended Kalman filter \\
\hline Observation sampling rate & 30s \\
\hline Precise products & $\begin{array}{c}\text { multi-GNSS final, rapid and ultra-rapid } \\
\text { products from WUH university center }\end{array}$ \\
\hline Frequency & L1, L2 and L5 \\
\hline Ionosphere & $\begin{array}{c}\text { ionosphere-free linear combination } \\
\text { a priori ZHD Saastamoinen model, ZTD } \\
\text { corrections and tropospheric gradients } \\
\text { estimated epoch-wisely }\end{array}$ \\
\hline Troposphere & $5^{\circ}$ \\
\hline Cut-off elevation angle & igs14_2062.atx \\
\hline Antenna model & applied (FES2004) \\
\hline Ocean tidal loading & CODE DCB monthly product \\
\hline $\begin{array}{c}\text { Differential code biases } \\
\text { (DCB) files }\end{array}$ &
\end{tabular}




\subsection{Methodology of the evaluation}

The study focuses on two ways of PPP performance evaluation while using three different multi-GNSS products from the Wuhan university $A C$ and various combinations of GNSS constellations (G, GC, GE, GR, GRC, GRE, GREC). In the first step, data from all eight GNSS stations were processed over the full period and obtained daily coordinates were compared with those from the official IGS final weekly solution (International GNSS Service, 2020). 3d differences of daily positions from own processing and IGS final weekly solution were computed using the formula:

$$
\text { 3d_difference }=\left(\left(X_{\text {own }}-X_{\text {igs }}\right)^{2}+\left(Y_{\text {own }}-Y_{\text {igs }}\right)^{2}+\left(Z_{\text {own }}-Z_{\text {igs }}\right)^{2}\right)^{1 / 2}
$$

where $X, Y, Z$ correspond to individual coordinates, index own to a coordinate from own PPP solution and index igs to a coordinate from the IGS final weekly solution.

The IGS solution represent a robust positioning product computed as a combination of GPS+GLO solutions delivered by individual IGS ACs. In the second step, coordinates repeatability was computed and assessed for the full time period, again for various constellation combinations.

Days where any version of the precise product was not available were fully excluded from the presented statistical comparisons. No outlier elimination was applied for the final and rapid version of the product. A following approach was applied to exclude outlying values from the results provided by the ultra-rapid version of the product: if a difference in position from the own RTKLIB processing and the IGS final weekly solution exceeded a threshold of $30 \mathrm{~cm}$ at some GNSS station and at some day, results from this GNSS station at the particular day were completely excluded.

\section{RESULTS}

\subsection{Comparison of own PPP coordinates with the IGS final weekly solution}

Overall statistics of comparisons for three tested versions of precise products are presented in Figure 2. Most of the combinations processed with final and rapid product stayed below or at the level of $6 \mathrm{~mm}$ for standard deviation (STD) and $14 \mathrm{~mm}$ for Root-Mean-Square error (RMS) in 3D positioning what indicates a good quality of PPP static positioning in RTKLIB with precise products from the Wuhan university AC.

While final and rapid version of products reached mostly similar performance in terms of STD and RMS, ultra-rapid version performed approximately five to ten times worse. This is caused by using a single ultra-rapid file with predicted product available before the processing run for a $24 \mathrm{~h}$ window and not updating it with newer files published hourly by the AC. If always using the newest file with an ultra-rapid product with predicted orbits and clocks, the situation should be improved. Performance of PPP positioning based on the ultra-rapid product still could be improved while using a constellation combination including Galileo, as STD and RMS values obtained for GE, GRE, GREC were significantly lower than for other solutions. A potential reason of this situation might be a high stability of atomic clocks at Galileo satellites. On the contrary, the impact of using different constellations while utilizing rapid and final product was minimal. An exception for this was brought by the BDS 
system which inclusion always worsened the overall results, mainly for the rapid product. Although a variability of statistics at individual stations for the final version of precise product (see table 3) impacts the mean results, one signal seem to apparent. European stations performed closer to the IGS final weekly solution than stations in China while using GRE constellation and the situation was exactly opposite for the GRC constellation.
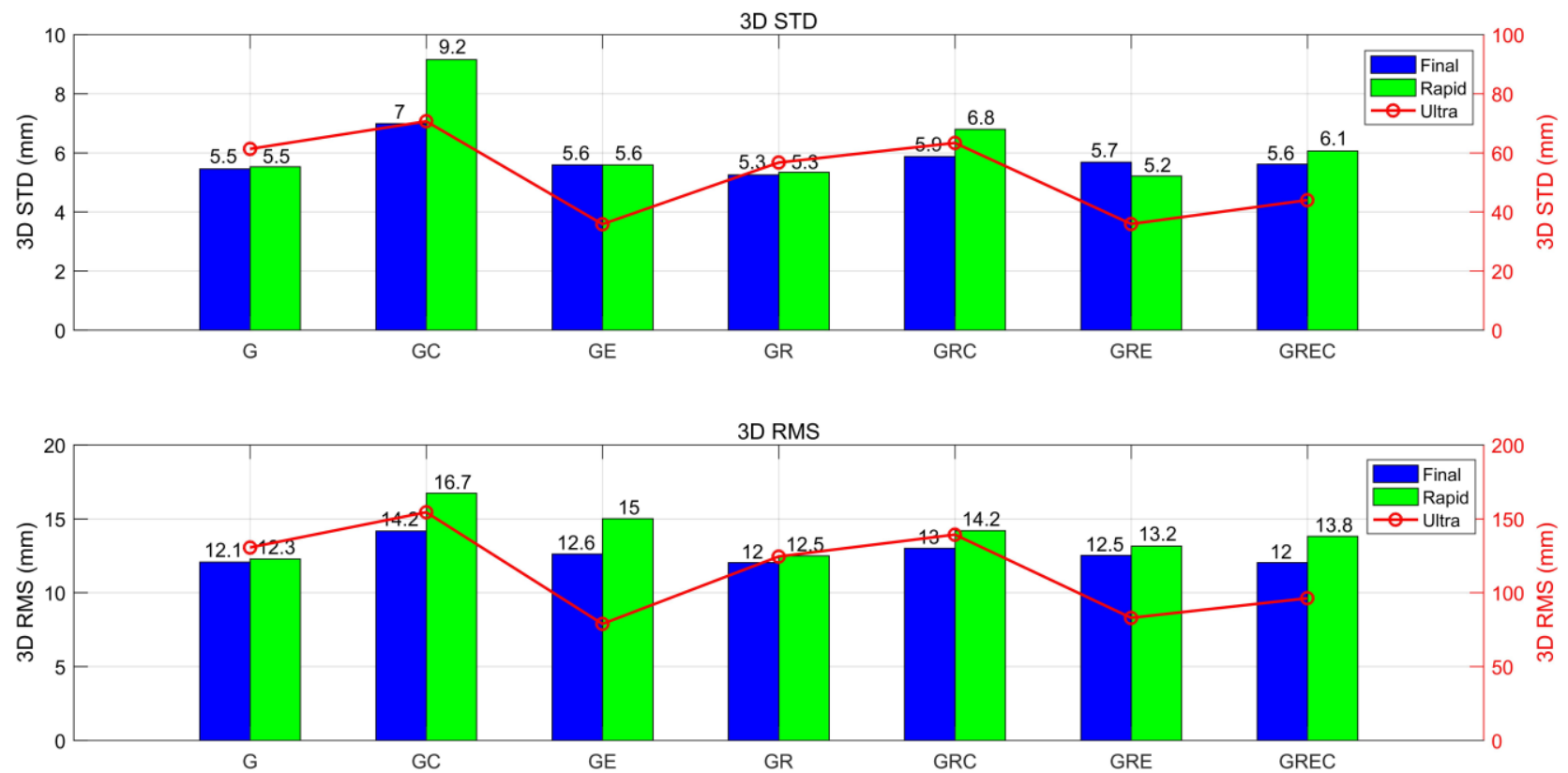

Fig. 4. STD (top) and RMS (bottom) values of 3D positioning difference between coordinates from own PPP processing using the three different types precise products (blue for final, green for rapid and red for ultrarapid version) and IGS weekly combined solution for selected eight GNSS stations.

Table 3. The Mean, RMS and STD values of the 3D positioning difference between PPP coordinates from own solution based on the final product from WUHAN analysis centre and the IGS final weekly solution, all values are in $\mathrm{mm}$.

\begin{tabular}{|c|c|c|c|c|c|c|c|c|c|c|c|c|}
\hline & \multicolumn{3}{|c|}{ GR } & \multicolumn{3}{|c|}{ GRE } & \multicolumn{3}{|c|}{ GRC } & \multicolumn{3}{|c|}{ GREC } \\
\hline & Mean & RMS & STD & Mean & RMS & STD & Mean & RMS & STD & Mean & RMS & STD \\
\hline GOPE & 9.8 & 11.5 & 6.1 & 8.1 & 9.5 & 5.0 & 10.7 & 12.5 & 6.6 & 8.9 & 10.5 & 5.6 \\
\hline MATE & 7.4 & 8.3 & 3.7 & 6.7 & 7.5 & 3.4 & 8.2 & 9.3 & 4.3 & 7.2 & 8.2 & 3.9 \\
\hline WTZR & 15.2 & 16.9 & 7.5 & 12.5 & 14.4 & 7.1 & 15.8 & 17.6 & 7.7 & 13.3 & 15.1 & 7.3 \\
\hline ONSA & 9.0 & 10.6 & 5.6 & 8.0 & 9.5 & 5.0 & 9.3 & 11.0 & 5.8 & 8.4 & 9.9 & 5.2 \\
\hline $\begin{array}{l}\text { Mean } \\
\text { Europe }\end{array}$ & 10.4 & 11.8 & 5.7 & 8.8 & 10.2 & 5.1 & 11.0 & 12.6 & 6.1 & 9.4 & 10.9 & 5.5 \\
\hline URUM & 12.4 & 13.2 & 4.5 & 19.1 & 20.9 & 8.4 & 11.1 & 12.2 & 5.1 & 15.5 & 16.7 & 6.4 \\
\hline JFNG & 7.6 & 8.4 & 3.6 & 10.4 & 11.5 & 5.0 & 9.2 & 10.4 & 4.8 & 8.3 & 9.6 & 4.8 \\
\hline WUH2 & 11.0 & 11.8 & 4.2 & 12.6 & 13.9 & 5.7 & 12.9 & 14.2 & 5.8 & 10.7 & 11.7 & 4.7 \\
\hline HKWS & 14.1 & 15.7 & 6.8 & 11.7 & 13.1 & 5.9 & 15.4 & 16.9 & 6.9 & 12.8 & 14.7 & 7.1 \\
\hline $\begin{array}{l}\text { Mean } \\
\text { China }\end{array}$ & 11.3 & 12.3 & 4.8 & 13.5 & 14.9 & 6.3 & 12.2 & 13.4 & 5.7 & 11.8 & 13.2 & 5.8 \\
\hline $\begin{array}{c}\text { Mean } \\
\text { all }\end{array}$ & 10.8 & 12.1 & 5.3 & 11.1 & 12.5 & 5.7 & 11.6 & 13.0 & 5.9 & 10.6 & 12.1 & 5.6 \\
\hline
\end{tabular}




\subsection{Repeatability of coordinates estimated with various satellite constellation combinations}

An impact of using various constellation combinations on coordinate's repeatability was examined and the results are provided in Table 4. Lower values represent a better stability of positioning while occurring differences can be attributed to a quality of individual GNSS stations, GNSS systems and to a quality of precise products provided for them by the Wuhan University AC. Since the lowest coordinate's repeatability was mostly reached by the GR combination or when processing GPS-only signals, inclusion of Galileo and BDS satellites did not provide any visible advantage for the realized daily static PPP positioning. Nevertheless, the situation can be very much different when processing data from a shorter observation time and/or in real-time mode and/or in locations with a limited view over the sky. Slightly lower coordinate's repeatability values reached by the final version product compared to the rapid version support their usage in the most critical applications.

Table 4. Mean position repeatability for final and rapid version of the precise products for individual constellation combinations. Two best results in each column are shown in bold.

\begin{tabular}{l|rrr|rrr|rrrr}
\hline \multicolumn{10}{c}{ Final precise product } \\
\hline \multicolumn{1}{c}{ All stations } & \multicolumn{3}{c}{ European stations } & \multicolumn{3}{c}{ China stations } \\
\hline $\begin{array}{l}\text { Conste } \\
\text { llation }\end{array}$ & North & East & Height & North & East & Height & North & East & Height \\
\hline G & $\mathbf{3 . 0}$ & $\mathbf{6 . 0}$ & 7.6 & $\mathbf{3 . 2}$ & 6.5 & $\mathbf{6 . 6}$ & $\mathbf{2 . 8}$ & $\mathbf{5 . 5}$ & 8.5 \\
GR & $\mathbf{2 . 9}$ & $\mathbf{5 . 3}$ & $\mathbf{7 . 4}$ & $\mathbf{2 . 8}$ & $\mathbf{5 . 4}$ & $\mathbf{6 . 7}$ & $\mathbf{2 . 9}$ & $\mathbf{5 . 2}$ & $\mathbf{8 . 0}$ \\
GE & 4.2 & 7.1 & 9.2 & 4.7 & 7.1 & 7.5 & 3.6 & 7.1 & 10.8 \\
GC & 3.7 & 8.4 & 7.8 & 4.1 & 8.8 & 7.0 & 3.3 & 8.0 & 8.6 \\
GRE & 3.6 & 6.3 & 8.9 & 3.7 & $\mathbf{5 . 5}$ & 6.9 & 3.6 & 7.1 & 10.8 \\
GRC & 3.2 & 6.0 & $\mathbf{7 . 4}$ & 3.3 & 6.2 & 7.0 & 3.1 & 5.9 & $\mathbf{7 . 9}$ \\
GREC & 3.6 & 6.0 & 8.1 & 4.0 & 6.2 & 7.0 & 3.2 & 6.3 & 9.2 \\
\hline
\end{tabular}

Rapid precise product

\begin{tabular}{l|rrr|rrr|rrr}
\multicolumn{4}{c}{ All stations } & \multicolumn{3}{c}{ European stations } & \multicolumn{3}{c}{ China stations } \\
\hline $\begin{array}{l}\text { Conste } \\
\text { llation }\end{array}$ & North & East & Height & North & East & Height & North & East & Height \\
\hline G & $\mathbf{3 . 9}$ & $\mathbf{7 . 2}$ & $\mathbf{8 . 2}$ & $\mathbf{3 . 6}$ & $\mathbf{7 . 0}$ & $\mathbf{7 . 1}$ & 4.3 & $\mathbf{7 . 4}$ & $\mathbf{9 . 3}$ \\
GR & $\mathbf{3 . 6}$ & $\mathbf{6 . 2}$ & $\mathbf{8 . 0}$ & $\mathbf{3 . 4}$ & $\mathbf{6 . 1}$ & 7.3 & $\mathbf{3 . 8}$ & $\mathbf{6 . 4}$ & $\mathbf{8 . 7}$ \\
GE & 5.7 & 9.4 & 9.6 & 6.0 & 9.7 & 7.9 & 5.4 & 9.0 & 11.3 \\
GC & 5.3 & 12.4 & 10.0 & 4.6 & 12.0 & 7.6 & 6.0 & 12.8 & 12.3 \\
GRE & 4.4 & 7.3 & 8.9 & 4.7 & 7.3 & $\mathbf{7 . 2}$ & $\mathbf{4 . 1}$ & $\mathbf{7 . 4}$ & 10.5 \\
GRC & 4.1 & 8.4 & 8.7 & 3.7 & 8.0 & 7.5 & 4.5 & 8.9 & 9.9 \\
GREC & 4.8 & 8.6 & 8.9 & 4.9 & 8.5 & 7.4 & 4.7 & 8.6 & 10.4 \\
\hline
\end{tabular}

\section{CONCLUSIONS}

We evaluated performance of PPP static daily positioning based on various constellation combinations and three different precise products provided by the Wuhan University AC. Through the data analysis of the two groups of stations, we found that European stations performed closer to the IGS final weekly solution than stations in China while using GRE constellation and the situation was exactly opposite for the GRC constellation. In the realized assessment, when utilizing rapid and final version of the products the constellation combination of GPS and GLO signals provided the best positioning results. On the other 
hand, an inclusion of Galileo to the processing utilizing ultra-rapid version of the product brought always a significant improvement in the coordinates accuracy and stability.

\section{REFERENCES}

Bahadur, B. and Nohutcu, M. (2019) Comparative analysis of MGEX products for postprocessing multi-GNSS PPP. Measurement 145, 361-369. doi:10.1016/j.measurement.2019.05.094.

Geng, T., Zhang, P., Wang, W., Xie, X. (2018) Comparison of Ultra-Rapid Orbit Prediction Strategies for GPS, GLONASS, Galileo and BeiDou. Sensors, 18, 477. doi:10.3390/s18020477.

Guo, J., Xu, X., Zhao, Q., Liu, J. (2016) Precise orbit determination for quad-constellation satellites at Wuhan University: strategy, result validation, and comparison. Journal of Geodesy, 2016, 90(2):143-159. doi:10.1007/s00190-015-0862-9

Guo, F., X. Li, X. Zhang, Wang, J. (2017) Assessment of precise orbit and clock products for Galileo, BeiDou, and QZSS from IGS Multi-GNSS Experiment (MGEX). GPS Solutions, 21, 279-290. doi:10.1007/s10291-016-0523-3.

Li, X., Pan, L., Zhang, X., Liu, J., Li, X. (2017) Performance Evaluation of Single-frequency Precise Point Positioning with GPS, GLONASS, BeiDou and Galileo. Journal of Navigation, 70, 3, 465-482. doi:10.1017/S0373463316000771.

Li, X., Zhu, Y., Zheng, K., Yuan, Y., Liu, G., Xiong Y. 2020. Precise orbit and clock products of Galileo, BDS and QZSS from MGEX since 2018: Comparison and PPP validation. Remote Sensing, 12, 9. doi:10.3390/RS12091415.

Montenbruck, O., Steigenberger, P., Prange, L., Deng, Z., Zhao, Q., Perosanz, F., Romero, I., Noll, C., Stürze, A., Weber, G., Schmid, R., MacLeod, K., Schaer, S. (2017) The Multi-GNSS Experiment (MGEX) of the International GNSS Service (IGS) -

Achievements, Prospects and Challenges. Advances in Space Research 59(7), 16711697. doi:10.1016/j.asr.2017.01.011.

Steigenberger, P. and Montebruck, O. (2020) Consistency of MGEX Orbit and Clock Products. Engineering 6, 8, 898-903. doi:10.1016/j.eng.2019.12.005.

Takasu, T. (2009) RTKLIB: Open Source Program Package for RTK-GPS. FOSS4G 2009. Tokyo, Japan, November 2, 2009.

Zhou, F., Cao, X., Ge, Y., Li, W. (2020) Assessment of the positioning performance and tropospheric delay retrieval with precise point positioning using products from different analysis centers. GPS Solutions, 24, 12. doi:10.1007/s10291-019-0925-0.

Zumberge, J. F., Heflin, M. B., Jefferson, D. C., Watkins, M. M., Webb, F. H. (1997) Precise Point Positioning for the Efficient and Robust Analysis of GPS Data from Large Networks. Journal of Geophysical Research, 102 (B3). doi:10.1029/96JB03860. 